\title{
Motile Sperm to Total Sperm Ratio Measurement
}

National Cancer Institute

\section{Source}

National Cancer Institute. Motile Sperm to Total Sperm Ratio Measurement. NCI

Thesaurus. Code C147433.

The determination of the ratio of motile sperm compared to total sperm present in a sample. The measurement may be expressed as a ratio or percentage. 